\title{
Avoiding loss of energy in a petrochemical industry, operation and design
}

\author{
S. Ávila ${ }^{1, *}$, A.Kiperstok ${ }^{1}$, B.Braga ${ }^{1}$, R. Kalid ${ }^{1}$ \\ ${ }^{1}$ Federal University of Bahia, Salvador, Brazil \\ *Corresponding author. Tel: +00557188977855, E-mail:avilasalva@gmail.com
}

\begin{abstract}
The challenge of economic and environmental sustainability demands a better way to manage production in the industry when treating energy consumption and emission of greenhouse gases. The reduction of greenhouse gases promoters are using: renewable energy matrix that can capture the $\mathrm{CO}_{2}$, renewable energy resources and, production activities with better efficiency in thermal systems. The industry segment contributes over $33 \%$ for $\mathrm{CO}_{2}$ emissions and it can be reduced through: energy integration in designs, intensifying the process and, better efficiency of utilities in the routine. The objective is demonstrates that, if global industry reduce at least $25 \%$ of thermal energy losses, $20 \%$ of losses of steam, and if change combustible oil to renewable in 33,8\% proportion, the greenhouse effect reduce in 33\%. The methodology to achieve reduction of $\mathrm{CO}_{2}$ emission includes: Preliminary assessment, Strategies, Specific Programs, Restrictions analyzes and measurement of results. Between strategies are actions on operation, design and business chain. Between programs there are: evaluations about utility control and management; biomass economic chain viability; and, actions to recover steam losses on design. The restrictions are to implement politic programs in society and industry segment to change patterns becoming possible thermal energy reduction and renewable combustible substitution. The projected results on reduction of $\mathrm{CO}_{2}$ in industry emissions are summed and almost overcome target of 21,6 $(20,4)$ GTY. The segments of society can prepare similar programs and transform exercise in practice giving better quality of life for earth population.
\end{abstract}

Keywords: Energy efficiency, Utility management, Industry Sustainability

\section{Nomenclature}

GTY Giga ton per year

IEA International Energy Agency

BRIC Brazil, Russia, India and China

\author{
MMI Man Machine Interface \\ CW Cooling Water \\ Biom Biomass
}

\section{Introduction}

This paper aims to demonstrate that, integrated actions of industries can achieve the target reduction in $\mathrm{CO}_{2}$ generation by greater energy efficiency in unit operations and by replacing the oil and gas fuels by biomass. After discussion about the industrial segment impact causing the greenhouse effect, topics of thermal efficiency and renewable energy resources are discussed. Then some activities and calculation methods are suggested for achieving the goals of reducing the generation of $\mathrm{CO}_{2}$.

According to Johan Rockstrom and others [1] [2] the challenges to sustaining life on planet earth (sustainable) depend on the care of large environmental requirements. These requirements are conditions for the stabilization of the atmosphere and return to equilibrium between the species and nature as they did before the uncontrolled growth of world economy. Climate change is one of the uncontrolled factors indicating the need for urgent action to reduce emissions of $\mathrm{CO}_{2}$, the main reason. Several programs and initiatives such as the gradual change of the current oil energy by renewable resources should be performed to prevent the growth and maintenance of the economy causing uncontrolled situations in nature and in particular in global climate.

To avoid the impact of gases contributing to air pollution, scientists seek to reduce its generation at source and reduce its inventory too. So they propose a series of actions resulting from studies that treat about the possible sources of energy and energy transformations, from 
2010 to 2050, by IEA - International Energy Agency [3]. According to the IEA study, in 2005 $\mathrm{CO}_{2}$ emissions to the atmosphere were the order of 28 GTY (Giga Ton per year), and imagining that, with the growth of global economies and emerging countries especially BRIC, the issue will be 62 GTY $\mathrm{CO}_{2}$. With the work proposed here and in several initiatives by the conscious world, we intend to achieve by 2050 a situation of greater sustainability by reducing $\mathrm{CO}_{2}$ emissions to around $14 \mathrm{GTY}$, or, half emission of 2005. Humanity needs to cut emissions from 2010 to 2050 on 48 GTY of $\mathrm{CO}_{2}$ (considering that very little was achieved from 2005 to 2010). Scientists from IEA [3] estimated options about contribution of human activities to emission reduction. From this study, the opportunities to reduce inventory of $\mathrm{CO}_{2}$ on atmosphere are located in different sectors of the economy. Energy sector has more potential for reduction with $20 \mathrm{GTY}$ of $\mathrm{CO}_{2}$, industrial sector with half the quota, $10 \mathrm{GTY}$ of $\mathrm{CO}_{2}$, transportation sector with $13 \mathrm{GTY}$, and urban areas with $15 \mathrm{GTY}$ of $\mathrm{CO}_{2}$.

Within the industrial sector, the opportunities to reduce $\mathrm{CO}_{2}$ generation are: end-use efficiency of fuel utilization and use of new renewable energy resources, using as knowledge base some researches and services in petrochemical, refine and metallurgical industries in Brazil at TECLIM, clean technology research group inside UFBA, Engineering School. These issues are very important to the industry and can be classified as strategic to their survival. The best efficiency in the end-use of fuel is due reductions achieved from thermal energy consumption in furnaces and boilers allowed by new criteria to control these operations proposed to petrochemical industry. New scenery of combustible changing is constructed with substitution of oil by regional biomass in petrochemical industry (thermal-power facility).

\section{Methodology}

The Methodology to achieve the reduction of this green house gas presented in Figure 1, is divided in: definition of target (total quantity of emission that will be reduced), preliminary assessment, principal strategies, for each strategy definition of a program to be implemented at industrial segment, restrictions analyzes, and, expected results and respective measurement tools. This paper develops programs that treat these strategies: (1) reduction of thermal energy consumption and (2) use of biomass to decrease emissions of $\mathrm{CO}_{2}$.

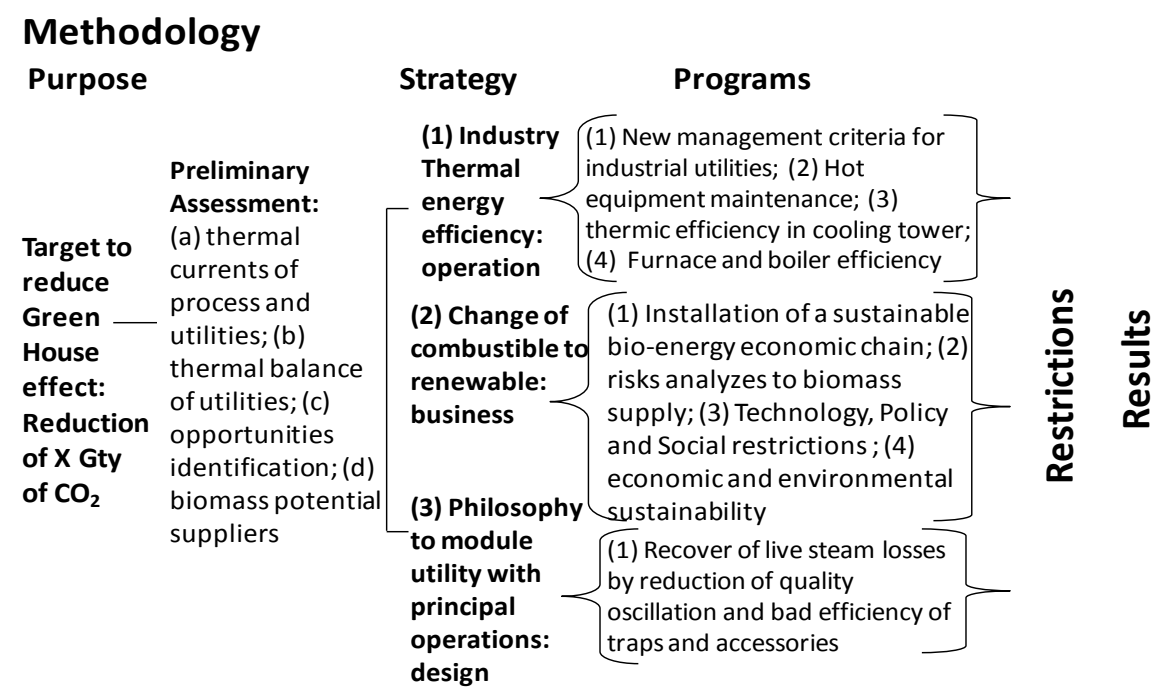

Figure 1. Methodology to investigate about reduction of $\mathrm{CO}_{2}$ emission by energy control

In these exercises the responsibility to exchange energy type and reduction of thermal energy loss causing reduction in fuel use are of industry. These exercises can point the way for new business with respect to energy consumption and reduction in $\mathrm{CO}_{2}$ generation. It means that 
industry intends to achieve a reduction of 12 GTY of $\mathrm{CO}_{2}$ from burning fuel and 8.4 GTY of free captured $\mathrm{CO}_{2}$ by photosynthesis after $\mathrm{CO}_{2}$ balancing with burning biomass.

\subsection{Strategy 1: Thermal Energy Efficiency at Industry, a research case}

The methods to increase energy efficiency depend on knowledge about energy balance and tasks related to control of thermal energy, cooling and heating systems at industry. Apart from knowledge availability and tasks well-planned, it is important reviewing conduct of the technical groups about management of utilities in the industry. A research about energy control was performed in a local Petrochemical Company [8] and proposes activities: (1) Planning and programming of Production allowing best decision-making in production scheduling (distribution of energy to activity); (2) Greater efficiency in cooling towers and systems allowing reduction of volatile products and hot energy consumption (temperature profile of separation columns); and (3) Efficiency of heat transfer in hot systems (boilers, furnaces, steam distribution, traps, condensate, and turbines) due to criteria of: projects, assemblies, operation, and thermal charge not compatible with the scale causing heat stress.

Although some of these issues involve the operation and maintenance of plants, the criteria of new projects must be adjusted using above standards, leading to a lower investment, to achieve the goal of greater efficiency in the use of fuel at industry and services. The article by Richard Doornbosch [3] present that the part concerning the reduction of fuel consumption is $12 \mathrm{GTY}$ of $\mathrm{CO}_{2}$, reference number for the industrial sector. The purpose is to work in a more efficient use of cold and hot energy to reduce consumption combustible thus generating smaller quantity of $\mathrm{CO}_{2}$ into the atmosphere.

To achieve better thermal performance in cooling and heating systems, heat balances were made in research cases at petrochemical [8], oil and metallurgical industry, where: (A) in the balance of the cooling towers are pointed out possibility of recovery losses, improving the thermal performance; (B) in the balance of boilers was identified recovery energy due to: incomplete burning, and failure on steam generation (bad operational procedures $\rightarrow$ low availability); (C) in the balance of furnace, the heat is too large by radiation, and the use of thermal energy to heat the reaction depends on: configuration of the tubes, complete burning of the furnace, and good insulation to prevent passage of heat through the equipment walls. Figure 2 descript part of topologies to study thermal performance.

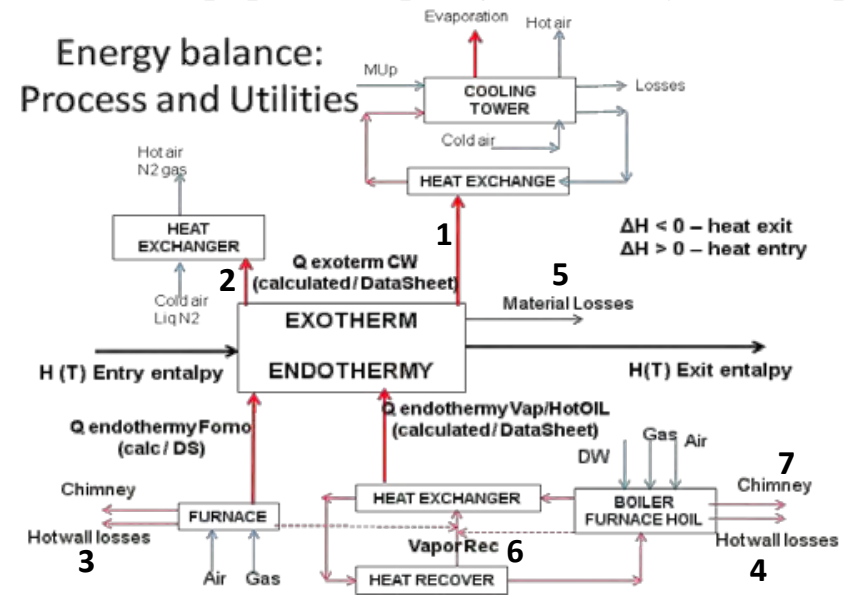

1 - Quality of CW and reflux; 2 - Removal of excess heat - thermal inadequate planning; 3 - Losses at wall furnace due to ingress of cold process fluid; 4 - Losses at wall boiler and operational inefficiency in purges; 5 Losses due flare materials by higher volatile content at the top of separation equipment; 6 - Traps, separators, process control, incorrect scale of equipments causing loss of alive steam; 7 - Losses in chimneys by not recover of residual heat.

Figure 2. Topology of direct and indirect heat transfer [9] 


\subsection{Strategy 2: Energy substitution, combustible mineral oils by biomass, a case}

With the forecast that world oil reserves are exhausted in about 100 years, there will be, in the medium and long term, environmental and economic viability to greater utilization of available biomass energy and currently is found in nature generating methane, most striking than carbon dioxide to the greenhouse effect. The total use of biomass as fuel for industry depends on some difficult to be worked as: complicated logistics, model of business, and need to increase the efficiency of combustion in furnaces and boilers. Biomass has the advantage of being a natural process that performs photosynthesis where the removal of $\mathrm{CO}_{2}$ occurs from the atmosphere, thus promoting favorable carbon balance. Assuming that each kilogram of $\mathrm{CO}_{2}$ generated from burning of biomass has direct equivalence for each kilogram of $\mathrm{CO}_{2}$ captured from atmosphere, we try to relate in Table 1, different types of Brazilian biomass.

Table 1- Comparison between different biomass and diesel

\begin{tabular}{lcccc}
\hline \multicolumn{1}{c}{ Biomass } & $\mathbf{g C O}_{2} / \mathbf{k g}$ Biom & $\mathbf{M J} / \mathbf{k g ~ B i o m}$ & Quantity Biom GTY & ${ }^{*} \mathbf{C O}_{\mathbf{2}} \mathbf{G T Y}$ \\
\hline Sugar can bagass & 0,075 & 15,49 & $200 \mathrm{E}-3$ & 0,08 \\
Black liquor & 998,79 & 13,40 & 2 E-3 & 0,002 \\
Coconut fiber & 1310,87 & 17,59 & 0,42 E-3 (peel, fiber) & 0,0002 \\
Cake/ Glycerin & 1885,77 & 25,30 & 2,2 E-3 (5\% biofuel) & 0,0023 \\
Total & & & 204,62 E-3 = 0,2 GTY & 0,0845 \\
\hline
\end{tabular}

The biomasses chosen are present in abundance in Brazil, due to the large production of sugar cane industry, producing about 200 million tons of bagasse, the pulp industry producing about 9 million tons of black liquor, and the incipient biodiesel industry that generates about 2 million tons per year of glycerin and cake. The marketing of coconuts is quite common in Brazil and the waste generated, coconut peel and fiber, are good source of biomass.

\subsection{Proposed activities to be performed}

The Programs to increase Energy Efficiency and Mineral Combustible Replacement in the Industrial Segment are presented in table 2 and 3 to discussions.

Table 2 - Energy Efficiency Program

$\checkmark$ Energy balance for process integration and definition of production scheduling;

$\checkmark$ Thermal performance in cooling systems and towers to reduce the temperature of water;

$\checkmark$ Thermal performance in heating systems, boilers, furnaces, steam / condensate and oil, in an attempt to reduce wall losses, loss of live steam, the reuse of energy, equipment reliability through proper drainage, and additional measures;

$\checkmark$ Review the criteria for equipment design in operation by reducing the size of the plants and allowing to work with adjusted modules and not unequal growth of utilities;

$\checkmark$ Review the criteria for management of maintenance and operation (tasks with more human reliability) in industrial plants intending to increase the operational availability of systems for cooling and heating.

Table 3 - Renewable biomass replacement program

$\checkmark$ Mapping the biomass availability; $\quad \checkmark$ Installation of local clusters by biomass type;

$\checkmark$ Installation of processing plants to $\checkmark$ Define national and global economic adequacy the biomass; architecture for using biomass;

$\checkmark$ Prepare managers in biomass area; $\quad \checkmark$ Promote the establishment of cooperatives;

$\checkmark$ Construct logistics scheme; $\quad \checkmark$ Training the cooperative managers. 


\section{Program of activities to increase thermal energy efficiency, Strategy 1, research case}

Assuming that the petrochemical plants and industry in general are in high charge/load, under thermal stress, the plants need to install additional equipment, or practicing high reflux flow in the distillation unit operations or similar. After performance tests conducted in the thermal cooling systems, some recommendations about proper operation can reduce by $15 \%$ or more, the temperature of cold water. Thus, fitting temperatures at the top of the decanter vessels, it reduces the reflux without losing the quality of final products, in bottom and top of equipments. If the premise that the proportion of decreasing the need for reflux ratio is equivalent to decreasing for hot utility at the bottom of the equipment, means that the reduction of steam consumption achieve the same, 15\% (\%RTEP1).

Some investigations are performed to reduce top temperature as result of cooling system (based on research case [9] and services): audit programs, calculations, process and operation investigations, and thermal performance tests discussed in Figure 3. The probably activities suggested are: change distribution of top cold pool, maintenance of top valves, vibration analyzes of fans, installation of side filters, temperature control measure with minimum of one decimal, calculation of concentration cycle based on good precision parameters, check of humidity of atmosphere and others. Other possibilities to reduction of losses are due to recovering of energy from: better insulation of hot equipment wall, increase of continuity in furnaces and boilers caused by increasing of human and operational reliability, diminish of mass losses to flare with cold temperature at column top, diminish of loss on energy recovery systems (condensate) by better control of steam quality. All these possibilities can increase the yield from $88 \%$ to $93 \%$, saving $10 \%$ of fuel consumption to generate steam and fuel consumption in furnaces (\%RTEP2). Summing possibilities of energy economy from cooling tower (15\%) with better operation and design of hot systems $(10 \%)$, we can achieve $25 \%$ of decreasing of combustible consumption (\%RTEP=\%RTEP1+\%RTEP2).

The hot utility project (steam and condensate) have flexibility to increase $15 \%$ when compared with the design capacity, different from the case of large equipment (cooling towers, reactors, separators, heat exchangers and others) with the possibility to lift charges between 50 to $80 \%$ more than project charge. Thus, in debottlenecking design, the review of projects is poorly made for utilities generating non conformities with loss of live steam above $25 \%$ (\%RSE). We consider, in the calculations, the possibility of recovery at least of $25 \%$ of live steam lost to the atmosphere.

Third Situation

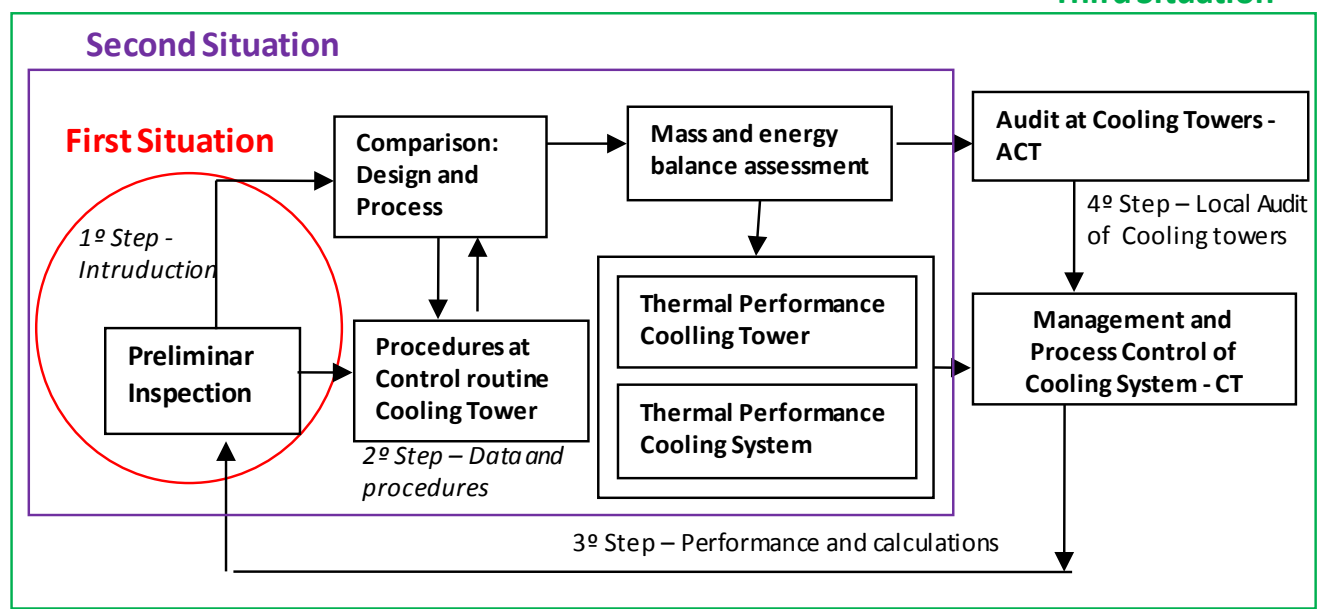

Figure 3. Energy management and audit of cooling system, based on research cases/services 
Join knowledge from operation of equipments with technology, including knowledge about human factors in MMI of equipments and including process intensification concerns, is possible to change the design criteria for equipment and processes increasing certainty and decreasing rate of the flexibility of capacity (reducing the engineering coefficients of ignorance in design). So with project of smaller equipments in conjunction with the project of appropriate utility systems increase the load of plant in industrial modules instead of debottlenecking, reducing than, the losses of live steam and reducing factory investment.

Estimation based on Petrochemical Industry $X$ in Brazil and Global Ones (Table 4). Based on data from large petrochemical $\mathrm{X}$ in Brazil, the annual production of ethylene is around 142,000 tons per year, and global ethylene production in 2010 was 142 million ton per year [4]. Thus, the calculation of fuel oil consumption and $\mathrm{CO}_{2}$ generation for petrochemical industries can be multiplied, for exploratory calculations, by 1000 (thousand) that represents all the petrochemical companies worldwide. Thus, for the production of plant X of 260 thousand tons/year and consumption index $16.5 \mathrm{GJ} /$ ton, this means all the energy consumption of around 4.3 million GJ/year. Whereas the average fuel PCI is $(43000 \mathrm{KJ} / \mathrm{Kg})$ 43 GJ per ton of fuel for the plant X. Annual consumption of fuels is 100 thousand tons of fuel per year for one plant in place X $(0,0001 \mathrm{Gton} / \mathrm{Y})$. For calculation to all petrochemicals, in exploratory way, it is considered $0,1 \mathrm{GTY}$ of fuel.

Table 4 - Data an formula for calculation Petrochemical Industry (Local $X$ and Global)

Pet EGP (Ethylene Global production) $=142.000 .000$ ton per year

Pet EXP (Ethylene Local production $X)=142.000$ ton per year

RelG/X (Relation Global/Local) $=$ PetEGP/PetEXP $=1000$ petrochemical estimated world

PPetX (Production of Petrochemicals at $X)=260.000$ Ton $/ Y$

CIPetX (Consumption Energy/Mass Index, Petrochemical X) = 16,5 GJ/Ton

CcombX (Consumption of combustible per year at $X)=\operatorname{PPet} X * C I P e t X=4.300 .000 \mathrm{GJ} / Y$

COPCI (Combustible Oil - PCI) $=43$ GJ/Ton of oil

FCPetX (Consumption of fuel to Petrochemical X) $=$ CcombX/COPCI $=100.000$ Ton of oil/Y

FCPet $X=0,0001$ Gton $/ Y=1 E-4$ Gton $/ Y$

FCPetGlobal(Global Consumption fuel to 1000 Petrochemical) $=100.000 .000 \mathrm{Ton} / \mathrm{Y}=0,1 \mathrm{GTY}$

RelG/X = PetEGP/PetEXP

CcombX $=$ PPet $X^{*}$ CIPet $X$

FCPet $X=$ CcombX/COPCI

FCPetGlobal $=$ FCPetX $*$ RelG/X

General Equation to consumption fuel at Global Petrochemicals indystries

FCPetGlobal $=(($ PPetX $*$ CIPetX $) /$ COPCI $) *($ PetEGP $/$ PetEXP $)$

Estimation based on Global Industry (Table 5). Considering that $1 \mathrm{~kg}$ of Carbon (C) generates $3 \mathrm{~kg}$ of $\mathrm{CO}_{2}$, giving approximately $2.5 \mathrm{~kg}$ of $\mathrm{CO}_{2}$ per $\mathrm{kg}$ of fuel. Thus $0,1 \mathrm{GTY}$ of fuel generates $0,25 \mathrm{GTY}$ of $\mathrm{CO}_{2}$. If we consider that $1 \%$ of industry is of petrochemical type [8] then total industry generates $25 \mathrm{GTY}$ of $\mathrm{CO}_{2}$. If recovery of $25 \%$ of $\mathrm{CO}_{2}$ by thermal efficiency and recovered is equivalent to $6.25 \mathrm{GTY}$, fulfilling the quota of efficiency in fuel consumption (12 GTY) for 1000 of petrochemicals X. This recovery is possible with better thermal performance of the separators from better operation of cooling systems and reduction of heat stress. If you consider the projected area, where you can recover $50 \%$ of live steam lost in the area, is reduced $25 \%$ of total $\mathrm{CO}_{2}$, since no generation of $12.5 \mathrm{GTY}$ which is higher than the target of $25 \%$ from 25 GTY of $\mathrm{CO}_{2}$, or 6.25 GTY. 
Table 5 - Data an formula for calculation Global Industry and decrease of $\mathrm{CO}_{2}$

GICCO2 (Generation Index CCO2) $=3 \mathrm{~kg} \mathrm{CO} / 1 \mathrm{~kg}$ of Carbon

GICO2Fuel (Generation Index CO2Fuel) $=2,5 \mathrm{~kg} \mathrm{CO} / 1 \mathrm{~kg}$ fuel $=2,5$ ton $\mathrm{CO}_{2} /$ ton fuel

PCO2PetX (Production of CO2 at X) = GICCO2Fuel * FCPetX = 2,5 E-4 Gton $\mathrm{CO}_{2} / \mathrm{Y}$

PCO2GTotalIndX (Total Ind Production of $\mathrm{CO}_{2}$ at X) = 2,6 E-2 Gton $\mathrm{CO}_{2} / \mathrm{Y}^{1}[8]$

Relation $($ Pet $/$ Total Ind $X)=(P C O 2 P e t X /$ PCO2GTotalIndX $)=1 \%$

PCO2PetG (Production of $\mathrm{CO}_{2}$ ) = FCPetGlobal * GICO2Fuel=0,25 Gton $/ Y$ of $\mathrm{CO}_{2}$

PCO2IndG (Prod of $\left.\mathrm{CO}_{2}\right)=$ PCO2PetG/ Relation $=25 \mathrm{GTY}$

$\% R T E P=\% R S E=25 \%$ (recovered steam by thermal programs - operation and design)

RTEP, Recovered by Thermal Energy Production $=(\% R T E P * P C O 2 I n d G)=(25 \% * 25$ GTY $)$

$=6,25 \mathrm{GTY}$ of $\mathrm{CO}_{2}$; RSE (Recovered by Steam economy) = production and design = $(\%$ RSE*PCO2IndG $)=(25 \% * 25$ GTY $)=6,25$ GTY of $\mathrm{CO}_{2}$; Total Recovered $(\mathrm{TR})=12,5$ GTY

TR $=\{(\%$ RTEP+\%RSE $) *[($ FCPetGlobal $*$ GICO2Fuel $) /($ PCO2PetX/PCO2GTotalIndX) $\}$ (6)

\section{Program of Activities to combustible substitution: biomass related to strategy 2}

Brazil [5] [6] [7] is an agricultural country and has large area of land available for food crops, has ample opportunity to use the biomass generated as a natural substitute of petroleum. Because of this trend, in very near future, there is a need for the government to invest in productive arrangements to provide this biomass for energy and industrial segment. For this change in the energy supply chain, it is required to mapping sources of biomass, defining the inventory economically feasible to tie their strategies, including political, technical, economic, environmental, ethical and seasonal risks. This Petrochemical Industry in study intends to meet the environmental paradigms to reduce greenhouse gases (carbon balance favorable due to increased carbon sequestration), and meet global energy demand.

There are some steps that the government, together with the industries and society in general must accomplish: - Develop network of institutions and companies with roles to enable installation of a sustainable bio-energy economic chain; - Analyze risks to regular supply of biomass; - Identify restrictions in: Technology, Policy and Social aspects; - Ensure the economic and environmental sustainability. Between policy challenges, there are: prepare economic local clusters, check on the participation of society (cooperatives in logistics and sorting) in this new economic activity, and development of technology to Bio-energy.

\section{Discussion of results}

In the global, if it is possible to reduce $25 \%$ of fuel consumption resulting from energy efficiency program and reduces $20 \%$ absolute of live stream to atmosphere is sufficient to meet the challenge posed by the IEA, a reduction of 12 GTY. In the biomass, considering the estimated of last four cases (sugar can bagass, coconut, cake/glycerin from biodiesel, and black liquor), achieves a $0.0845 \mathrm{GTY}$ of $\mathrm{CO}_{2}$, needing a biomass matrix at least 100 times bigger, including other biomass and other countries like China and India in trying to reduce carbon emissions into the atmosphere. If you reach this goal, with 8.45 GTY versus 9.6 GTY $\mathrm{CO}_{2}$, quota demanded to be reduced. As mentioned before, the industry emits 25 GTY of $\mathrm{CO}_{2}$ from fuel combustion, is intended to reduce 8.45 equivalent to $33.8 \%$ of the diesel currently used, when you know that above the goal number of $10 \%$, a third part of necessity, demanding strong economic and political organization and efforts around the biomass.

\footnotetext{
${ }^{1}$ * General Relation Industry/Petrochemical in Bahia/BR, place X, [8]
} 


\section{Conclusion and Restrictions}

Work with energy efficiency is simple when Industry management gives importance to utilities as: steam (generated by water and heat from combustible), direct heat to furnace (generated by heat from combustible burning), and cooling water (that depends of cooling tower work). The difficulties are to change managers' decision model that analyze short term problems and does not work to increase human and operational reliability. One other concern is about the necessity to change design criteria preparing factories in smaller size.

Despite the great potential of Brazil to the wide use of biomass, it is not still efficient to process and distribute products in biomass segment; it depends of governments' infrastructure in logistics area. Although there are many searches for new technologies in which the fuel is biomass, it does have large-scale policies or actions that make the distribution of this form of biomass for industry, already ready for use. Therefore, it is necessary to analyze the economics chain in the vertical form, including all activities in the life cycle of different biomasses. For the energetic matrix change to renewable one, some multi-attributes assessment (environment, economic, ethical, policy, social) to choice biomass must be done. The criteria for choice of matrix must be analyzed in biomass to prevent, for lack of planning, the projects unviable after long-term, development policy for biomass, availability of materials, supply guarantees, social and environmental benefits.

\section{References}

[1] Johan RockstrOm et al. A safe operating space for humanity. Macmillan Publishers: Nature, vol 461, p. 472/475. 2009.

[2] Johan RockstrOm et al. Planetary Boundaries: Exploring the safe operating space for humanity. Ecology and Societ. 36 p. 2009.

[3] Richard Doornbosch et al. Round Table on Sustainable Development: Mobilizing Investments in LowEmission Energy Technologies on the Scale Needed to Reduce the Risks of Climate Change. Organisation Economic Cooperation /Development. 53p. 2008.

[4] Global Industry Analysts. World ethylene market to cross 160 million tons by 2015, according to new report by global industry analysts. Researched on January 2011. http://www.chemicalonline.com/article.mvc/World-Ethylene-Market-To-Cross-160Million-0001. 2008.

[5] Painel Florestal. Brasil cresce 7,3\% na produção de celulose e fortalece investimentos. Researched on 2010: http://painelflorestal.com.br/noticias/celulose/9721/brasil-cresce-73-na-producao-de-celulose-e-fortalece-investimentos. Original source: Bracelpa. 2010.

[6] Biodieselbr.com. Biodiesel no Brasil. http://www.biodieselbr.com/biodiesel/brasil/biodiesel-brasil.htm. 2011.

[7] John Deere. Cana/açúcar/alcool: preços firmes no curto e no longo prazo. Original source: Carlos Cogo Consultoria Agroeconômica. http://www.deere.com.br/pt_BR/ag/veja_mais/info_mercado/sugar_cane.html

[8] IBGE - Instituto Brasileiro de Geografia e Estatística - IBGE. Sustainable Development Indexes of Brazil - Greenhouse gas emissions. 443 p. 2010.

[9] Teclim Research EcoBraskem - UFBA. Final Report: Thermal Energy Balance at UNIB/ Braskem. 2009. 